

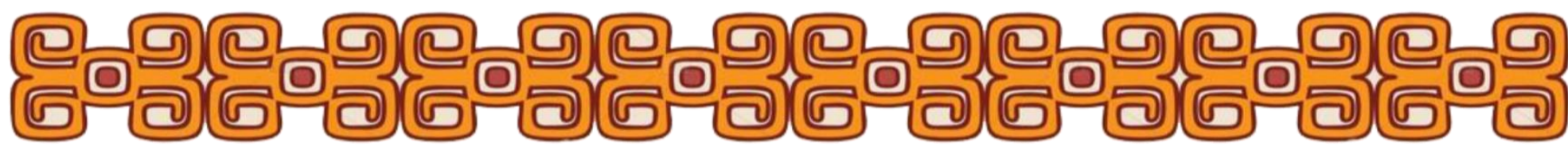

Apesar disso, a questão ambiental realmente passou a ganhar fôlego em meados do século $X X$, quando as atitudes predatórias da humanidade se converteram em graves problemas ambientais, de proporções irreversíveis; numa tentativa de encontrar equilíbrio na relação homem-natureza e buscando amenizar os prejuízos deixados pelo chamado desenvolvimento.

No enfrentamento dessa crise ambiental, a bandeira da sustentabilidade é levantada por diversos grupos sociais de todo o mundo, uma educação para mudanças de comportamentos e atitudes, no que diz respeito à conservação da natureza, permeada por uma consciência cidadã passa a ser elaborada e instituída. Conferências, seminários, toda uma legislação é construída para formular as bases da educação ambiental, com o intuito de formar cidadãos responsáveis pela sua sociedade.

No Brasil, o processo de institucionalização da educação ambiental pelo governo federal se iniciou em 1973. Neste período foi criada a Secretaria Especial do Meio Ambiente (SEMA), que tinha o compromisso de organizar e definir o papel da EA no contexto nacional, legislando e estruturando (DIAS, 2000)

Com a Política Nacional de Meio Ambiente estabeleceu-se a inclusão da educação ambiental em todos os níveis de ensino, incluindo a educação da comunidade, objetivando a capacitá-la para a part icipação ativa na defesa do meio ambiente (DIAS, 2000).

É desta política pública que o presente trabalho vislumbra tratar, contextualizando a implantação de órgãos gestores no cenário nacional e a forma como a dinâmica de formação pedagógica dos atores sociais envolvidos está ocorrendo. Para tanto, optou-se por uma análise bibliográfica, dividida em três partes.

A primeira parte desta análise traz uma rápida conceituação a respeito do que vem a ser política e o quanto cabem várias interpretações acerca deste termo, resgatando-se a visão de autores que escrevem amplamente sobre as políticas setoriais. Foi, ainda, inserida neste trabalho como uma forma de demonstrar que a ciência política, no tocante a polít icas setoriais, é um campo de análise bastante recente e que carece de embasamento teórico para desenvolver um maior grau de generalização.

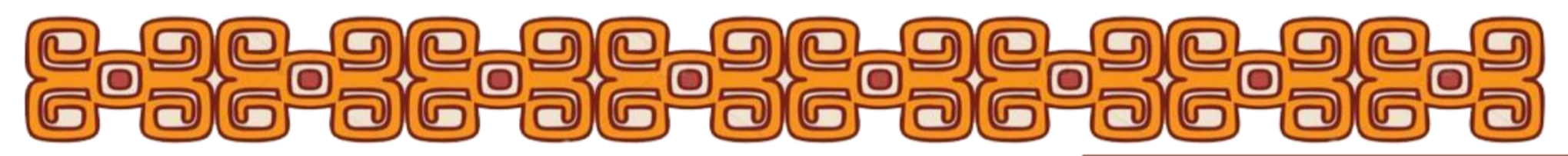




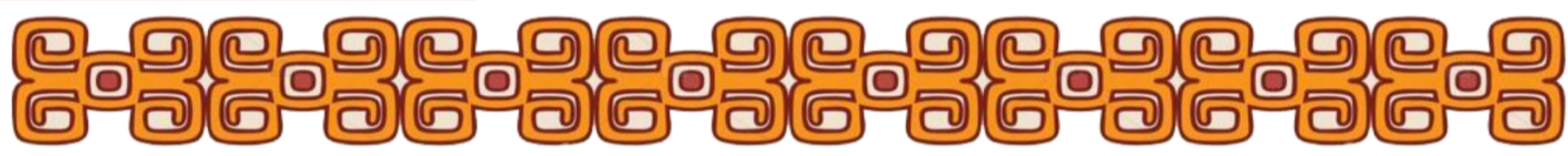

É nesta última abordagem que se encontra a análise de campos específicos de políticas públicas como as políticas econômicas, financeiras, tecnológicas, sociais ou ambientais. No entanto, o interesse da análise de políticas públicas não se restringe meramente a aumentar o conhecimento sobre planos, programas e projetos desenvolvidos e implementados pelas políticas setoriais. Visando à explanação das "leis e princípios próprios das políticas específicas, a abordagem da 'policy analysis' pretende analisar "a inter-relação entre as instituições políticas, o processo político e os conteúdos de política" com o "arcabouço dos questionamentos 'tradicionais' da ciência política (WindhoffHérit ier, 1987, p. 7, apud FREY, 2000, p. 214).

Segundo Frey (2000), essa vertente de pesquisa da ciência política, políticas públicas, ganha expressão na década de 50 nos Estados Unidos e na década de 1970 na Alemanha. No Brasil, é bastante recente estudos sobre políticas públicas. Nesses estudos, ainda esporádicos, deu-se ênfase ou à análise das estruturas e instituições ou à caracterização dos processos de negociação das políticas setoriais específicas.

Normalmente, tais estudos carecem de um embasamento teórico que deve ser considerado um pressuposto para que se possa chegar a um maior grau de generalização dos resultados adquiridos. Na verdade, a falta de teorização é uma crítica comumente direcionada à 'policy analysis'. Porém, a falta de teoria é explicável, se levarmos em consideração o interesse de conhecimento próprio da policy analysis', que é, a saber, a empiria e a prática política. (FREY, 2000, p. 215).

\section{A POLÍTICA PÚBLICA DE EDUCAÇÃo AMBIENTAL: UM DEBATE SOBRE A NECESSIDADE DE FORMAÇÃO CONTINUADA AOS PROFESSORES}

O surgimento da Educação Ambiental no cenário internacional está relacionado à crise provocada pela expansão do modelo de desenvolvimento capitalista industrial, vivida a partir das décadas de 1950 e 1960 do século XX. Sua proposta surge na Conferência de Estocolmo, mas é somente na Conferência de Tbilisi que ela figura sistematizada em texto, com seus princípios e diretrizes (ROSA et al., 2015).

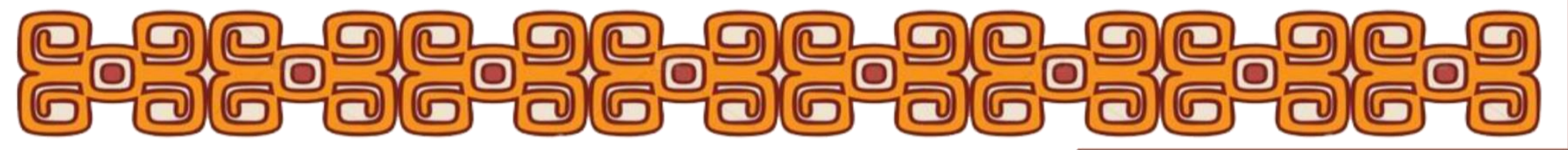




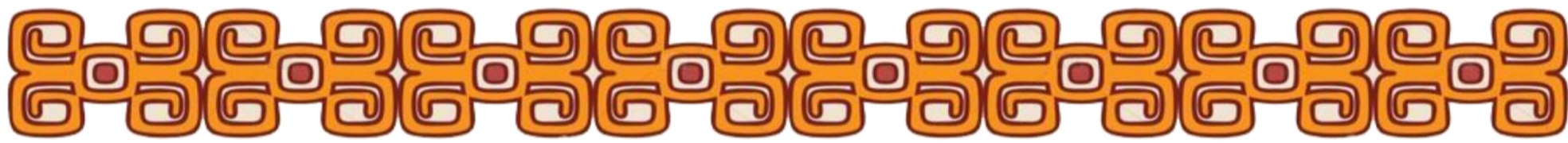

A inovação proporcionada pelo nascimento da EA se fundamenta por sua busca em possibilitar maior criticidade e conhecimento sobre a interação do humano com o meio, além de conscientizar a sociedade sobre os seus direitos e responsabilidades. A EA, portanto, contribuiu para a compreensão da realidade de uma forma mais complexa por perpassar diferentes campos científicos (ROSA et al., 2015).

A Educação Ambiental, segundo a Lei Federal no 9.795 (BRASIL, 1999), que instituiu a Política Nacional de Educação Ambiental (PNEA), caracteriza-se pelos processos por meio dos quais os indivíduos e a coletividade constroem valores sociais, conhecimentos, habilidades, at itudes e competências, voltados para a conservação do meio ambiente, bem de uso comum do povo, essencial à sadia qualidade de vida e à sua sustentabilidade.

No art. $2^{\circ}$, da lei supracitada, a interdisciplinaridade metodológica e epistemológica da educação ambiental é enfatizada como "componente essencial e permanente da educação nacional, devendo estar presente, de forma articulada em todos os níveis e modalidades do processo educativo, em caráter formal e não formal. Esta lei fornece um roteiro para a prática da educação ambiental e na sua regulamentação (Decreto no 4281/2002) indica o Ministério da Educação e do Meio Ambiente como órgãos gestores dessa política, destacando que,

A construção da educação ambiental como política pública, implementada pelo Ministério da Educação e Cultura (MEC) e pelo Ministério do Meio Ambiente (MMA), implica processos de intervenção direta, regulamentação e contratualismo que fortalecem a articulação de diferentes atores sociais (nos âmbitos formal e não formal da educação) e sua capacidade de desempenhar gestão territorial sustentável e educadora, formação de educadores ambientais, educomunicação socioambiental e outras estratégias que promovam a educação ambiental crítica e emancipatória. As políticas públicas em educação ambiental implicarão uma crescente capacidade do Estado de responder, ainda que com mínima intervenção direta, às demandas que surgem do conjunto articulado de instituições atuantes na educação ambiental crítica e emancipatória (SORRENTINO et al.,2005, p. 290).

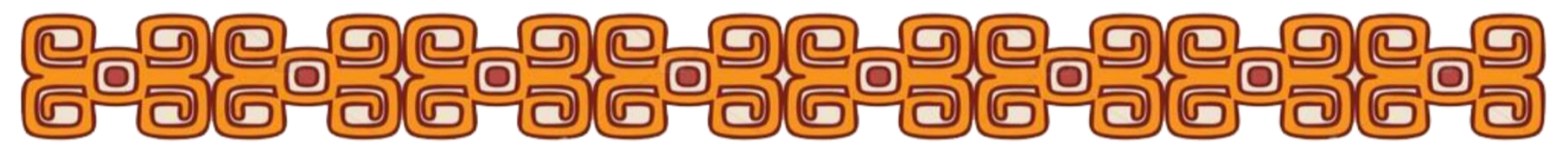




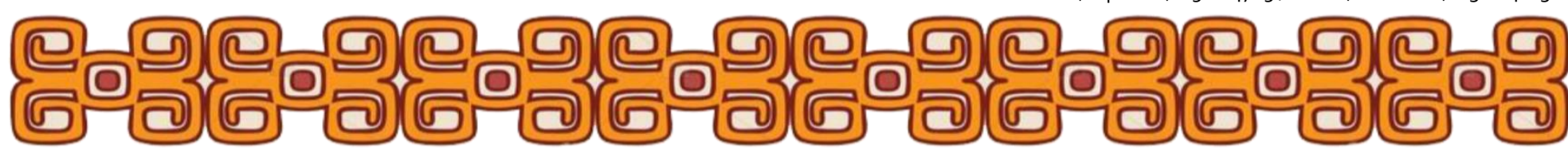

A educação ambiental insere-se nas políticas públicas do Estado brasileiro de ambas as formas, como crescimento horizontal (quantitativo) e vertical (qualitativo), pois enquanto no âmbito do MEC pode ser entendida como uma estratégia de incremento da educação pública, no do MMA é uma função de Estado totalmente nova (SORRENTINO et al., 2005).

As políticas públicas em educação ambiental implicarão uma crescente capacidade do Estado de responder às demandas que surgem do conjunto articulado de instituições atuantes na educação ambiental crítica e emancipatória (SORRENTINO, et al., 2005). Para tanto, a Educação Ambiental deve promover uma estreita vinculação entre os processos educativos e a realidade, estruturando suas atividades em torno dos problemas concretos que se impõem à comunidade (DIAS, 2000).

No contexto de surgimento e implantação da EA, observando-se os arranjos inst itucionais que se fizeram necessários, bem como as mudanças que tiveram que ocorrer nas secretarias de educação e unidades escolares em vários aspectos - curricular, infraestrutural, pedagógico (planejamentos, conferências, capacitações de professores) -, entre outros, nasce o questionamento a respeito da formação dos profissionais que precisarão atuar na "linha de frente" para que esta política pública seja efetivada nas escolas.

Para Kaplan e Loureiro (2011), a educação ambiental (EA) estabeleceu uma relação com a educação repleta de contradições e distanciamentos, com poucos e rasos diálogos, o que resulta em dois problemas determinantes: dificuldades da comunidade escolar no entendimento da complexidade da $E A_{;}$e, os educadores ambientais, não raramente, mostram desconhecer a dinâmica escolar, o que os leva a produzir afirmações de cunho normat ivo, prescrit ivo e idealizado relat ivos à inserção da EA nas escolas (LOUREIRO, 2007, apud KAPLAN e LOUREIRO, 2011).

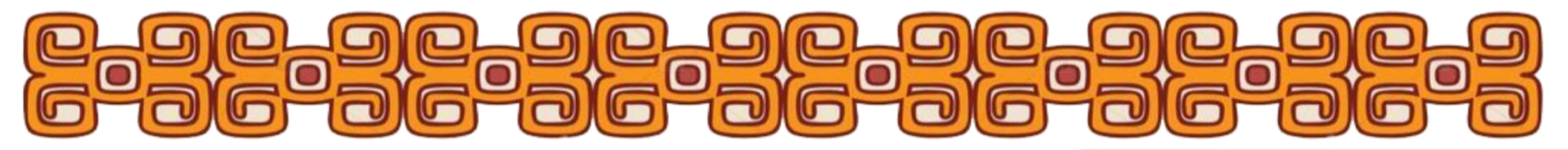




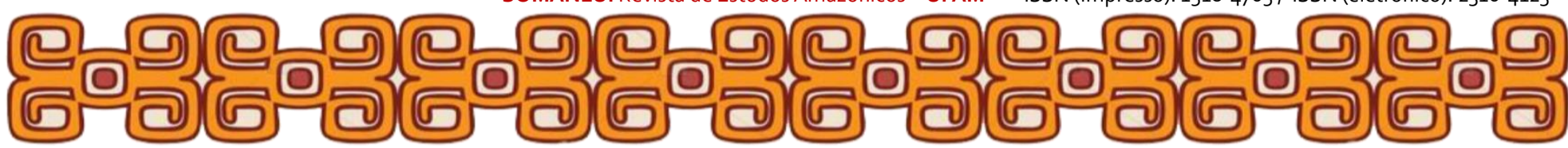

prejudicando o trabalho desenvolvido (TRAJBER; MENDONÇA, 2007, apud TOZONI-REIS et al., 2013).

Tozoni-Reis et al. (2013), na pesquisa 'A inserção da Educação Ambiental na Educação Básica: que fontes de informação os professores utilizam para sua formação', onde entrevista cerca de trezentos professores que trabalham em escolas de 14 municípios da região central do Estado de São Paulo, chegou à algumas conclusões que servem de argumento para o debate proposto neste artigo.

Uma grande quantidade dos professores afirmou realizar suas pesquisas e seus estudos sobre a EA no mesmo material didático oferecido aos alunos, dentre os quais estão: as revistas, jornais e os livros didáticos. Os professores citam como suas fontes de informação: revistas $(23 \%)$, internet $(14 \%)$, materiais paradidáticos $(14 \%)$, livro didático $(13 \%)$, jornais (10\%), apostilas (6\%), livros em geral (6\%), vídeos, filmes e músicas (4\%), cursos, palestras e panfletos $(3 \%)$, matérias acadêmicas (3\%) e programas de TV $(3 \%)$, seguidos de projetos e práticas educativas (2\%), legislação, normas e diretrizes (1\%) e artigos em geral (menos de 1\%) (TOZONI-REIS et al., 2013).

Conforme a análise de Tozoni-Reis et al. (2013), a maior parte das fontes utilizadas configuram-se como materiais didáticos. As revistas e os jornais foram as fontes de informação de maior peso na formação dos professores como educadores ambientais (33\% do total). Além da revista Nova Escola, a mais citada pelos professores, outras revistas com citações significat ivas foram: Veja, Superinteressante e Época. As revistas científicas foram insignificantemente citadas, visto que houve uma única citação da revista Ciência Hoje, que traz conteúdos mais próximos às disciplinas de ciências, biologia, química, física e matemática.

As fontes de informação apontadas pelos professores são, na realidade, meios de comunicação para o grande público, não tendo como preocupação a transmissão de conhecimentos e conteúdos mais elaborados do ponto de vista escolar, pois trazem informações genéricas para serem rápida e instantaneamente consumidas pelos leitores. Atividades com esse tipo de recurso exigem mediação constante dos professores para que

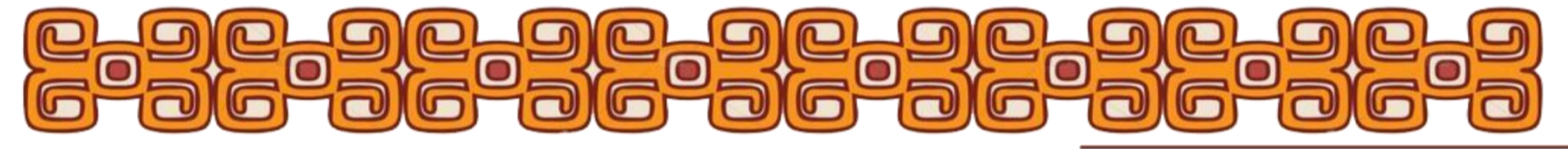




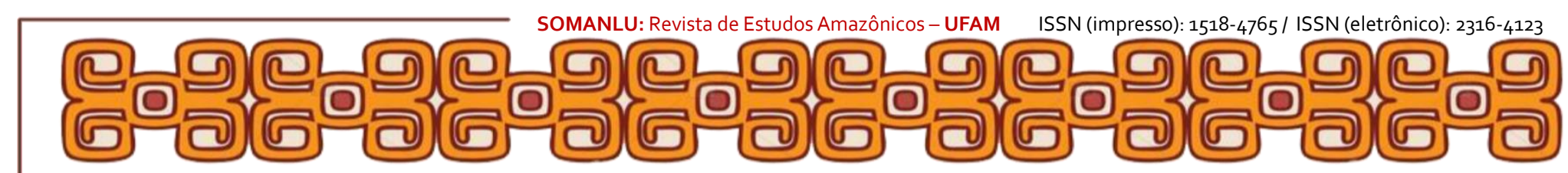

possa ser considerada uma atividade de ensino com qualidade, no sent ido de apropriação crít ica do saber elaborado pela cultura (TOZONI-REIS et al., 2013).

A situação preocupante, dessa prática educat iva ambiental, concentra-se no fato de que os conhecimentos são tratados de forma fragmentada e superficial em relação ao necessário domínio dos saberes escolares para a inserção da temát ica ambiental, revelando uma ação educativa muito mais próxima da ideia de consciência ingênua - no caso, sobre a temática ambiental - que discutiu Paulo Freire (1989 apud TOZONI-REIS et al., 2013), e do senso comum educacional discutido por Demerval Saviani (1991 apud TOZONI-REIS et al., 2013), quando sabemos serem necessárias a consciência crítica e a consciência filosófica por parte dos professores, uma demanda legítima e necessária a qualquer processo educat ivo em nossa sociedade (TOZONI-REIS et al., 2013).

A revista Nova Escola foi mais destacada no estudo por ter sido a mais citada pelos professores entrevistados. Segundo Tozoni-Reis et al. (2013) é uma revista produzida pelo Grupo Abril, que prioriza um vocabulário simplificado e a disseminação de muitas ilustrações que apresentam professores e alunos 'sorridentes'. Ao concebê-la como uma "expressão da semicultura" na sociedade globalizada contemporânea.

As fontes de informações citadas pelos professores, como as revistas e os jornais, ao divulgarem informações genéricas e superficiais sobre o tema ambiental para uma leitura de massas, não são publicações voltadas para a formação profissional e específica dos professores, se considerarmos essa formação sob a perspectiva da pedagogia históricocrítica. Essa situação se torna ainda mais inadequada se lembrarmos que os professores, em geral, utilizam-se destas informações e as reproduzem diretamente para os alunos, sem uma reflexão própria, mediada pelos seus conhecimentos específicos para a prática educat iva ambiental (TOZONI-REIS et al., 2013).

Além das revistas e jornais, outras fontes de informação indicadas pelos professores foram os materiais paradidáticos e a internet (igualmente $14 \%$ cada). Dentre os materiais paradidáticos, foram citados diversos materiais que não se caracterizam como aqueles que se apresentam com fins propriamente didáticos, e também não podem ser considerados

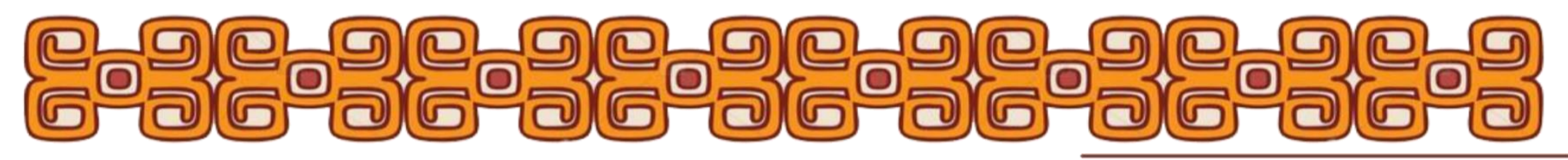




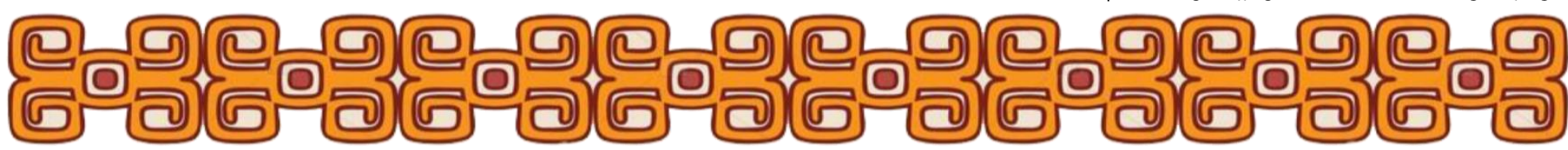

materiais ou fontes voltadas para a formação do educador ambiental. Muitos dos materiais citados estão relacionados a jogos, cartazes, panfletos, sites, gibis etc. A partir da forma como esse material foi apontado nas entrevistas, é possível se concluir que não são utilizados para a formação do professor como educador ambiental, mas estão mais próximos de recursos didáticos que os professores usam com seus alunos (TOZONI-REIS et al., 2013).

Assmann e Ceccon (2015), ao traçarem um perfil dos professores que trabalham na Educação Básica com Educação Ambiental, apontaram que a falta de interesse políticoeconômico e a Formação Continuada é o principal entrave dessa discussão, haja vista a maioria das escolas não possui um Projeto Político-Pedagógico (PPP) contextualizado de como será desenvolvida a EA, e seus professores anseiam por apoio e instrução.

Ainda no trabalho de Assmann e Ceccon (2015), há um destaque para uma questão bastante pertinente que é a falta de incentivos que as escolas sofrem por parte dos órgãos de governo, o que as torna pouco participativas e exclusas das discussões atuais sobre o tema. Esta falta de apoio dos órgãos governamentais/gestores serve de obstáculo para a efet ivação da aplicação das orientações cont idas em documentos of iciais, referentes à EA.

Existe uma lacuna na Formação Cont inuada dos professores, fato que ficou explícito nas entrevistas aplicadas. Há uma constante necessidade de propostas para esta formação, sejam elas advindas de instituições governamentais ou não, desde que a instituição de ensino a que o professor esteja vinculado propicie esta continuidade. É a formação cont inuada que propiciará uma reflexão da prática pedagógica e a intervenção sobre ela, o intercâmbio de experiências, a atualização educativa, o desenvolvimento profissional e dos processos de comunicação, a integração entre a pesquisa e a escola, a divulgação dessas pesquisas (ASSMANN e SILVA, 2011; IMBERNÓN, 1994; MALDANER, 2000; SCHNETZLER, 2000, apud ASSMANN e CECCON, 2015, p. 587).

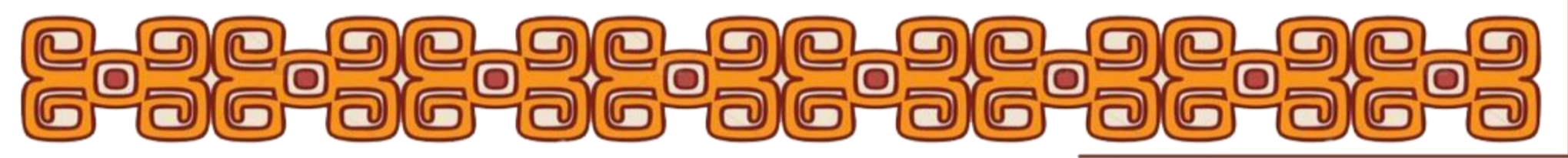




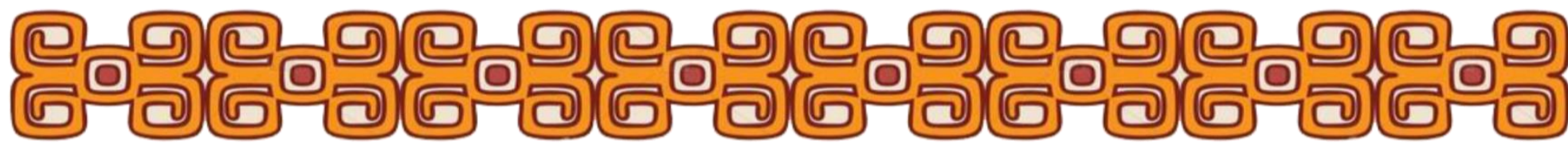

\section{CONSIDERAÇÕES FINAIS}

Com este trabalho, foi possível identificar como a política pública de educação ambiental tem fal hado em 'sua missão', haja vista tudo o que é discursado nos documentos oficiais está longe de se materializar.

Os professores, que são a mola propulsora do sistema educacional, os intermediadores desse complexo processo, sentem-se visivelmente abandonados pelos ministérios e secretarias que possuem, ou, pelo menos, deveriam possuir, os meios econômicos e políticos para efetivar esta política pública.

A formação cont inuada, que não passa apenas por uma questão quantitativa, tem sido deixada de lado ou tem acontecido de maneira bastante insatisfatória. A própria educação ambiental dentro de instituições de nível superior ainda se apresenta incipiente frente ao debate que já completou meio século.

A lentidão e a burocratização dos órgãos que pensam as políticas educacionais torna inviável a concret ização de projetos eficazes dentro das unidades escolares.

Um outro fator que também merece ser destacado é que a própria educação ambiental se formou diante de diversas correntes de pensamento, não há uma homogeneização ideológica, como muitas vezes se tenta demonstrar nos documentos que a regem. As políticas públicas de educação são permeadas de conflitos pelo poder, não que isso seja de todo ruim, pois as mudanças ocorrem em meio aos conflitos. No entanto, é importante buscar pontos de convergência para que o fazer pedagógico possa se sobressair.

Para desenvolverem um bom trabalho na questão ambiental, os professores precisam ter a possibilidade de conjugar teoria e prática, adquirindo a teoria, o conhecimento científico, por meio de estratégias est imulantes e incentivadoras e a prática longe da precariedade dos recursos materiais de pesquisa, pois sem material adequado e em quantidade suficiente para não há como realizar um bom trabalho.

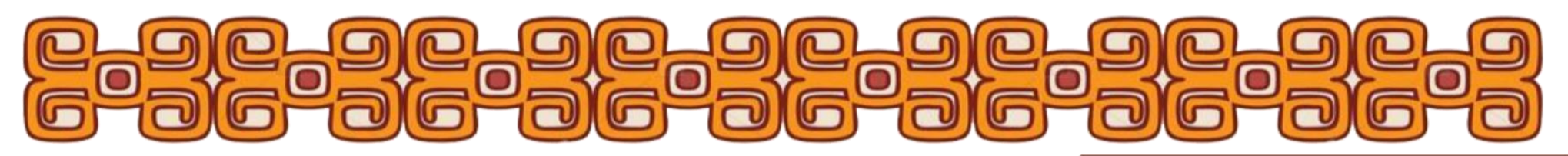




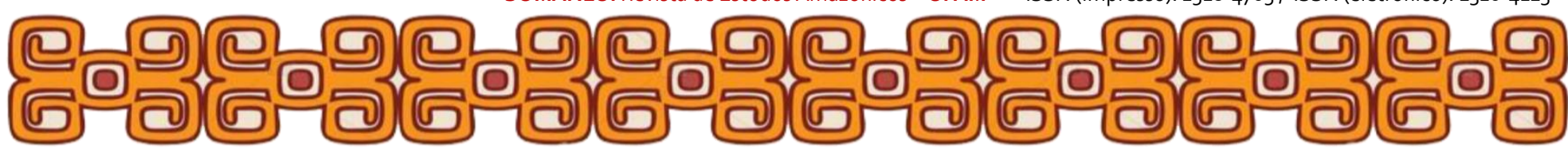

A EA não deve ser confundida com um tipo de instrução de caráter essencialmente técnico, que enquadra o aluno a determinados conhecimentos e habilidades e acaba não permitindo que o mesmo reconheça a origem dos problemas ambientais. O problema ambiental deve ser considerado primeiramente como um problema político e social, não como uma simples crise de gerenciamento da natureza, porque está bem mais enraizada socialmente.

Tanto o professor precisa estar preparado para conceder uma educação significat iva e crítica, no sent ido emancipatória, quanto o aluno precisa se ver enquanto ator consciente que não está à mercê de um aprendizado passivo, não apenas como um robô programado automaticamente para absorver informações.

A conscient ização somente ocorrerá e a EA realmente desempenhará seu papel na formação cidadã, a partir do momento que as pessoas sintam-se envolvidas e tenham sua atenção voltada para os problemas do mundo, compreendendo-os e sentindo-se também responsáveis por eles.

A escola, de modo geral precisa conhecer o Projeto Polít ico-Pedagógico para a part ir daí melhorá-lo e incluir, de forma adequada, a EA. Não é possível pensar em realizar EA sem falar em democracia ou cidadania.

Enquanto a EA for planejada por institutos e órgãos governamentais que desconheçam a real situação da comunidade escolar, seus problemas políticos, sociais, econômicos e culturais, isto é, enquanto a EA aparecer como uma política descolada da vida real, em políticas verticais, part indo de um pequeno grupo para a 'base da pirâmide' já se sabe o resultado: não durará muito tempo, não terá a cont inuidade que poderia ter e o resultado posit ivo que poderia lograr.

Dito desta forma, abre-se uma arena de possibilidades de discussões e debates a respeito dos argumentos aqui apresentados e de muitos outros que possam surgir a part ir desta leitura.

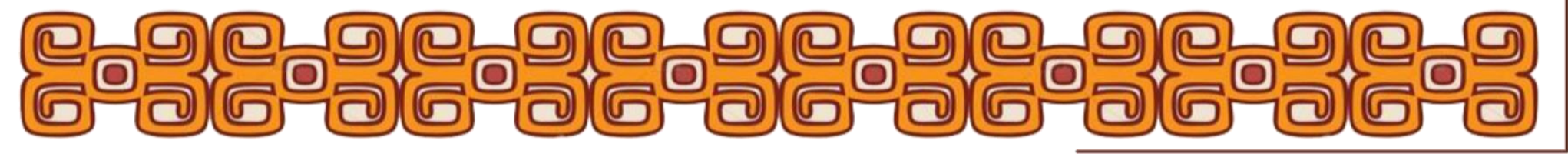




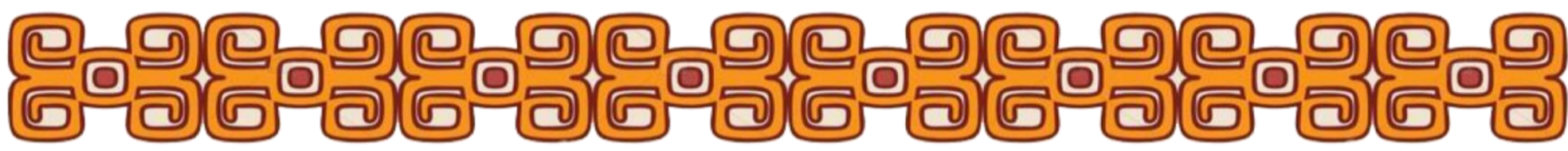

\section{REFERÊNCIAS}

ASSMANN, S. M.; CECCON, S. O que fazem as escolas que dizem fazer educação ambiental? Perfil dos professores nas escolas de ensino básico de Dourados - MS. Enciclopédia Biosfera, Centro Científico Conhecer - Goiânia, v.11, n. 20, p. 579-591, 2015.

ASSMANN, S. M.; SILVA, L. H. A. A articulação entre formação inicial e continuada de professores de ciências no processo de construção de saberes sobre o fazer docente de licenciandos em ciências biológicas. Dourados, 2011.

BACHRACH, P; BARATZ, M. S. Decisions and Nondecisions: An Analytical Framework. American Political Science Review, v. 57, n. 3, p. 632-642, 1963.

BRASIL. Lei n 9.795, de 27 de abril de 1999. Dispõe sobre a educação ambiental. Inst itui a Política Nacional de Educação Ambiental e dá outras providências. Diário Oficial da União, Brasília, DF, 28 abr. 1999.

DIAS, G. F. Educação ambiental: princípios e práticas. São Paulo: Editora Gaia, 2000.

EASTON, D. The Political System. New York: Knopf, 1953.

FREIRE, Paulo. Pedagogia do oprimido. 13. ed. Rio de Janeiro: Paz e Terra, 1989.

FREY, Klaus. Políticas Públicas: um debate conceitual e reflexões referentes à prática da análise de políticas públicas no Brasil. Planejamento e Políticas Públicas, Brasília, n. 21, p. 211-259, Jun. 2000.

HAM, Christopher; HILL, Michael. O processo de elaboração de políticas no estado capitalista moderno. Tradução de Renato Amorim e Renato Dagnino. 2. ed. rev. Londres, 1993.

HECLO, H. Policy analysis. Brit ish Journal of Political Science, v. 2, n. 1, p. 83-108, jan. 1972.

IMBERNÓN, F. La Formación y el Desarrollo Profesional del Profesorado: Hacia una nueva cultura profesional. Barcelona, Ed. Graó, 1994.

KAPLAN, L.; LOUREIRO, C. F. B. Análise crítica do discurso do Programa Nacional de Formação de Educadoras(es) Ambientais - ProFEA: pela não desescolarização da educação ambiental. Educação em Revista, Belo Horizonte, v. 27, n. 02, p.177-196, ago. 2011.

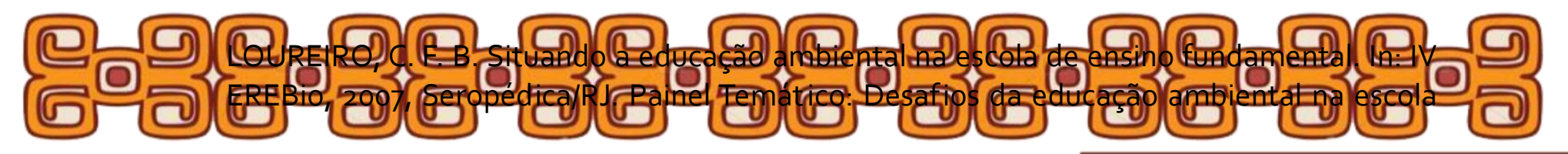




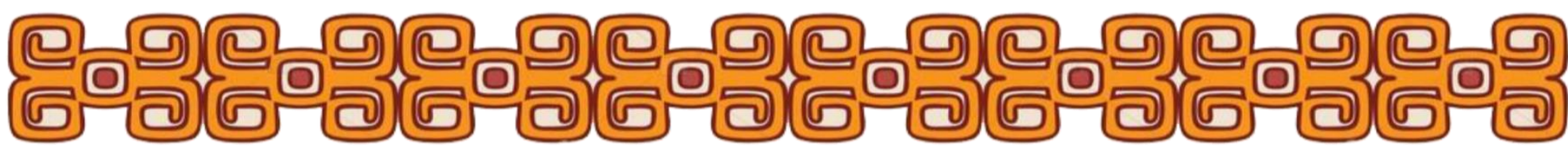

básica. IV Encontro Regional de Ensino de Biologia. Seropédica: SBEnBio/UFRRJ, v. 1, p. 1$11,2007$.

MALDANER, O. A. A formação inicial e continuada de professores de química. Editora Unijuí, 2000.

ROSA, Teresa da Silva et al. A educação ambiental como estratégia para a redução de riscos socioambientais. Ambiente \& Sociedade, São Paulo, v. XVIII, n. 3, p. 211-230, jul.-set. 2015.

RUA, Maria das Graças. Análise de Políticas Públicas: Conceitos Básicos. In: RUA, Maria das Graças; VALADAO, Maria Izabel. O Estudo da Política: Temas Selecionados. Brasília: Paralelo 15, 1998.

RUA, Maria das Graças. Políticas públicas. Florianópolis: Departamento de Ciências da Administração/UFSC, 2009. 130 p.

SAVIANI, D. Do senso comum à consciência filosófica. São Paulo: Autores Associados, 1991.

SAVIANI, D. Transformações do capitalismo, do mundo do trabalho e da educação. In: LOMBARDI, J. C.; SAVIANI, D. SANFELICE, J. L.(Orgs.). Capitalismo, Trabalho e Educação. Campinas: Autores Associados, HISTEDBR, p. 13-24, 2005.

SCHMITTER, Phillip. Reflexões sobre o Conceito de Política. In: BOBBIO, Norberto et al. Curso de Introdução à Ciência Política. Brasília: UnB, 1984.

SCHNETZLER, R. P. O professor de ciências: problemas e tendências de sua formação. In: SCHNETZLER, R. P. e ARAGÃO, R. M. R. (Orgs.). Ensino de Ciências: fundamentos e abordagens. Piracicaba. CAPES/UNIMEP, 2000.

SORRENTINO, M. et al. Educação ambiental como política pública. Educação e Pesquisa, São Paulo, v. 31, n. 2, p. 285-299, maio/ago. 2005.

TOZONI-REIS, M. F. C. A inserção da educação ambiental na escola. Bolet im TV Escola, v. 01, p. 46-54, 2008.

TOZONI-REIS, M. F. C. et al. A inserção da educação ambiental na educação básica: que fontes de informação os professores utilizam para sua formação? Ciência e Educação, Bauru, v. 2, n. 19, p.359-377, mar. 2013.

TRAJBER, R; MENDONÇA, P. (Orgs.). Educação na diversidade: o que fazem as escolas que dizem que fazem educação ambiental. Brasília: Secretaria de Educação Continuada, Alfabet ização e Diversidade, 2006.

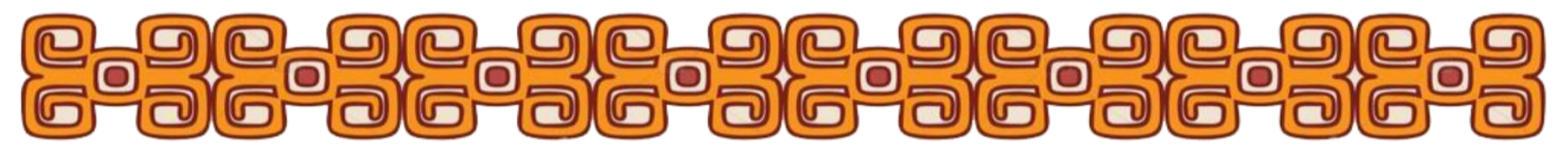




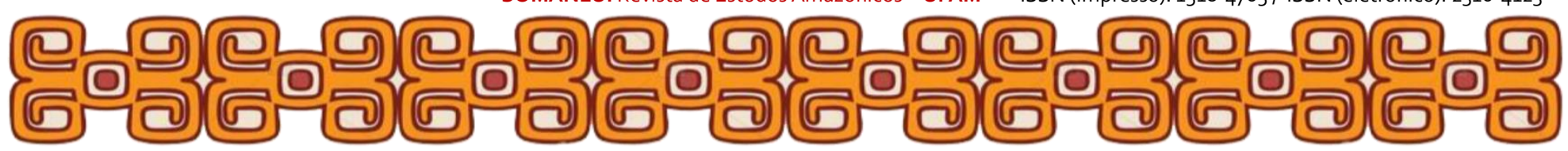

WINDHOFF-Héritier, Adrienne. Policy-Analyse: eine Einführung. Frankfurt am Main/New York: Campus, 1987.

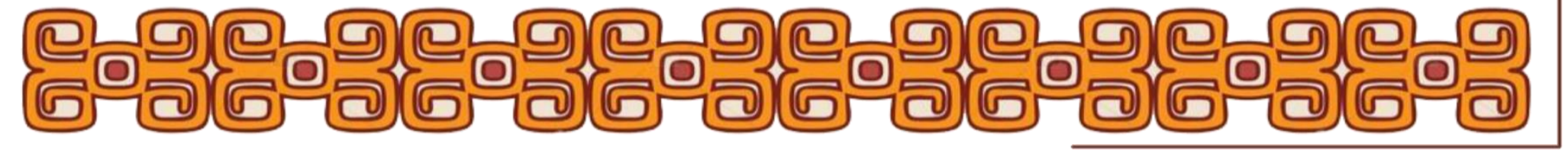

